\title{
Transplante de terceiro molar autógeno, uma alternativa ao implante dentário - Revisão de literatura
}

\section{Autogenous third molar transplantation, an alternative to dental implant - Literature review}

DOI: $10.46919 / \operatorname{archv3n1-003}$

Recebimento dos originais: $17 / 12 / 2021$

Aceitação para publicação: 18/01/2022

\author{
Romero Samarcos Mendes Pontanegra \\ Especialista em Implantodontia - UNIFIP Patos-PB \\ (Professor da Graduação da Faculdade Soberana de Saúde de Petrolina) \\ Av. Manoel dos Arroz, 85. Bloco 5 apt 204. Bairro Vila Mocó Petrolina-PE \\ E-mail: romerosamarcos@hotmail.com \\ Ricardo Herman Artur Ribeiro \\ Graduando Bacharelado em Odontologia \\ Faculdade Soberana de Saúde de Petrolina \\ Gabriel Silva Barboza dos Santos \\ Graduando Bacharelado em Odontologia \\ Faculdade Soberana de Saúde de Petrolina. \\ Emilly Emanuelly Oliveira da Silva \\ Graduanda Bacharelado em Odontologia \\ Faculdade Soberana de Saúde de Petrolina. \\ Cecilia Corcino de Lucena Camboim \\ Cirurgiã-Dentista - UNIFIP Patos-PB
}

\section{RESUMO}

Introdução: A manutenção da dentição natural com saúde e função durante a vida do paciente é vista como prioridade, todavia, existem perdas dentárias por doenças como a cárie e periodontite além de traumatismos que podem levar a extração do dente afetado. Uma possibilidade de tratamento é o transplante dentário, também conhecido como "prótese biológica" e está diretamente associado à situações socioeconómicas. Objetivos: O objetivo deste estudo foi investigar, por meio de uma revisão de literatura, a viabilidade da técnica de transplante dentário autógeno como alternativa ao implante dentário. A técnica discutida apresenta índice de sucesso elevado, mostrando-se uma excelente alternativa de tratamento. Materiais e Métodos: Foi realizado um levantamento bibliográfico no Pubmed, utilizando os descritores autotransplante, terceiro molar e reabilitação, onde foram selecionados artigos de acordo com os critérios de inclusão. Resultados: Vários estudos foram realizados com intuito de analisar a técnica e sucesso do transplante de terceiro molar como forma de tratamento em casos de perda precoce de molares. Alguns Cirurgiões-dentistas aplicaram a técnica quando a alternativa está relacionada ao baixo custo do tratamento. Conclusões: Conclui-se que a técnica tem um alto índice de sucesso, tornando uma alternativa viável e econômica para reabilitação protética oral natural.

Palavras-chave: autotransplante, terceiro molar, reabilitação. 


\section{ABSTRACT}

Introduction: The maintenance of natural dentition with health and function during the patient's life is seen as a priority, however, there are tooth loss due to diseases such as caries and periodontitis, in addition to trauma that can lead to the extraction of the affected tooth. One possibility for treatment is dental transplantation, also known as "biological prosthesis" and is directly associated with socioeconomic situations. Objectives: The aim of this study was to investigate, through a literature review, the feasibility of the autogenous dental transplant technique as an alternative to dental implants. The discussed technique has a high success rate, proving to be an excellent treatment alternative. Materials and Methods: A bibliographic survey was carried out in Pubmed, using the descriptors autotransplantation, third molar and rehabilitation, where articles were selected according to the inclusion criteria. Results: Several studies were carried out in order to analyze the technique and success of third molar transplantation as a form of treatment in cases of early molar loss. Some dentists applied the technique when the alternative is related to the low cost of treatment. Conclusions: It is concluded that the technique has a high success rate, making it a viable and economical alternative for natural oral prosthetic rehabilitation.

Keywords: autotransplantation, third molar, rehabilitation.

\section{INTRODUÇÃO}

A odontologia atual está cada vez mais próximo dos atos conservadores, orientando os pacientes sobre os benefícios da manutenção dental natural. Em situações da perda precoce dos dentes, alternativas para o tratamento reabilitador são sempre favoráveis e o transplante dentário autógeno é uma alternativa para a substituição de um molar perdido. ${ }^{1}$

Miller e Apfel foram os responsáveis por introduzirem o tratamento com transplante dentário na literatura. Após anos, Flemingem e Costich aperfeiçoaram a técnica e fundamentaram os sucessos e as falhas de acordo com a aplicabilidade do procedimento. ${ }^{234}$

Os dentes perdidos por extensa destruição coronária causado pela doença cárie principalmente, bem como, dentes com reabsorção radicular, periodontite e dentes que sofreram traumatismos são de fato estes que tem as principais indicações para tratamento com transplante autógeno. ${ }^{156}$

Os dentes que sofrem traumatismos podem evoluir com trincas no esmalte até avulsão e perda do elemento. Nestes casos, o cirurgião-dentista deve avaliar o osso alveolar além do dente que sofreu o impacto, com a finalidade de indicar ou não o transplante. Outros fatores devem ser analisados como a idade do paciente e o dente doador. ${ }^{7}$

Outros fatores também devem ser analisados, como a idade do paciente, o dente doador, a área receptora, o estágio de desenvolvimento do dente a ser transplantado, a técnica cirúrgica a ser executada e o tempo de permanência do dente doador sem aporte sanguíneo ${ }^{711}$. A presença de células saudáveis na superfície das raízes do dente doador é um fator importante para o sucesso da tratamento. ${ }^{11} 12$ 
A classificação dos transplantes dentários está relacionada com doador e receptor, além da formação do ápice radicular. O ideal é que no mínimo dois terços das raízes estejam formadas, assim as chances de sucesso tornam-se maiores. ${ }^{89}$

O procedimento passa a ser contraindicado quando o dente a ser transplantado possui tratamento endodôntico, ou, está com quadro infeccioso. Nessa situação o quadro de infecção necessita ser debelado anteriormente ao transplante ${ }^{9}$. Também é contraindicado quando a morfologia das raízes passa a ser complexa, necessitando de odontosecção, além dos dentes que possui grandes dimensões que não é adaptável ao alvéolo da área receptora. 610

Os benefícios para a utilização deste tratamento vão além do baixo custo quando comparado à outras possibilidades. Melhoria na estética do arco dental, manutenção da função mastigatória, preservação do processo alveolar e possiblidade de tratamento ortodôntico incluindo o dente transplantado faz parte das benfeitorias. ${ }^{11}$

Considerando dentro das opções de tratamento reabilitador após perda precoce de um molar permanente, o transplante autógeno foi considerado uma excelente alternativa protética principalmente em indivíduos em crescimento pois ajuda a preservar o osso alveolar e manter a saúde bucal controlada. ${ }^{12}$

\section{MATERIAIS E MÉTODOS}

Esta revisão de literatura foi realizada através de um levantamento bibliográfico no Pubmed, utilizando os descritores autotransplante, terceiro molar e reabilitação em, tendo como resultado o alcance de 109 artigos dos quais foram utilizados 12 para o estudo, obedecendo os critérios de inclusão e exclusão. Os critérios de inclusão foram: selecionar referências que retratam o tema proposto com foco principal na abordagem da indicação, contraindicação, técnica cirúrgica e aplicabilidade do tratamento, publicados em língua inglesa e portuguesa. Os critérios de exclusão foram: artigos com fuga de tema, não disponíveis de forma eletrônica e que possuem apenas o resumo disponível para o acesso.

\section{RESULTADOS E DISCUSSÃO}

No âmbito da Odontologia, vários estudos foram realizados e a técnica foi aplicada a fim de consolidar o tratamento com transplante dentário autógeno.

Em diversos casos clínicos mostra que o sucesso do tratamento está acompanhado da correta indicação, bem como, da análise minuciosa de todos os critérios para execução do tratamento.

O caso clínico apresentado por Warmeling segue o protocolo cirúrgico para exodontia de terceiro molar, onde foi diagnosticado lesão cariosa extensa no dente 26 e o dente 28 com possibilidade de autotransplante. Foi utilizado anestésico infiltrativo local com articaína 4\% e epinefrina 1:100.000, evoluindo para um procedimento minimamente traumático principalmente no dente 28 para manter os 
tecidos saudáveis. Após o transplante do dente 28 para o alvéolo do dente 26 foi feito uma contenção semirrígida do mesmo com auxílio dos dentes 25 e 27. Para o pós operatório imediato foi prescrito Amoxicilina 500mg um comprimido a cada oito horas por sete dias, ibuprofeno $600 \mathrm{mg}$ um comprimido a cada oito horas por três dias e digluconato de clorexidina $0,12 \%$, bochechos de doze horas por sete dias, iniciando vinte e quatro horas após o procedimento. Após oito meses de controle foi feito um novo exame de imagem e teste de sensibilidade pulpar com resposta positiva, um indicativo de revascularização e reinserção das fibras do periápice. ${ }^{6}$

O sucesso na reabilitação apresentado por Warmeling com a indicação correta e técnica cirúrgica aplicada corrobora com o sucesso obtido pelo caso clínico de Peixoto, no qual realizou o transplante dentário dos dentes 18 e 28 para reabilitação no alvéolo fresco dos dentes 46 e 37 . A mesma técnica foi aplicada, modificando apenas a contenção do dente transplantado, utilizando uma sutura compressiva para manter o dente em posição durante o período de cicatrização. ${ }^{61}$

\section{CONCLUSÃO}

Conclui-se que, a alternativa de autotransplante principalmente em pacientes jovens que possuem 2/3 das raízes dos terceiros molares em formação tem indicação relevante e altos índices de sucesso. Quanto a sua abordagem cirúrgica na Odontologia, torna-se um procedimento com baixo custo que viabiliza a reabilitação em determinados casos e pacientes. Dessa forma, podemos aplica-la clinicamente em situações que o paciente se enquadre dentro das indicações clínicas para reparar danos causados pela perda precoce de molares permanentes. 


\section{REFERÊNCIAS}

1. Peixoto AC, Melo AR, Santos TS. Transplante dentário: atualização da literatura e relato de caso. Rev. Cir. Traumatol. Buco-Maxilo-Fac., Camaragibe v.13, n.2, p.75-80, abr/jun. 2013.

2. Sebben G, Castilhos MDS, Silva RFC. Trans- plantes autógenos de terceiros molares inclu- sos. Rev ADppUCRS 2004; 5:109-111.

3. Hale ML. Autogenous transplants. oral Surg oral Med oral pathol 1956; 9(1):76-83.

4. Apfel H. Transplantation of the unerupted third molar tooth. oral Surg oral Med oral pathol. 1956; 9(1):96-8.

5. Pagliarin Fo, Benato M. Transplante dentário autógeno: apresentação de dois casos. Clin pesq odontol 2006; 2(3):231-40.

6. Warmeling $\mathrm{M}$, et al. Transplante dentário autógeno: revisão de literatura e relato de caso clínico. RFO UPF, Passo Fundo, v. 24, n. 2, p. 273-278, maio/ago. 2019

7. Consolaro A, et al. Transplantes dentários autógenos: uma solução para casos ortodônticos e uma casuística brasileira. R. Dental Press Ortodon Ortop Facial. Maringá, v.13, n.2, p.23-28, mar/abr. 2008.

8. Transplantation A, As D, For A. Transplante dental autógeno como alternativa para reabilitação oral: relato de caso. Uningá Rev 2013; 14(1):49-57.

9. Ravi kumar P, Jyothi M, Sirisha K, Racca K, Uma C. Autotransplantation of mandibular third molar: a case report. Case Rep Dent 2012; 2012:1-5

10. Jodas RPCRP, Rapoport A, Junqueira LCJLC, Baccarin LS, Moraes PC, Gati CAR, et al. Transplante dental bilateral: relato de caso clínico com acompanhamento de 9 anos. Rev Assoc Paul Cir Dent 2012; 66(1):30-5

11. Silva AFN. Transplante dentário autógeno. CESPU Repository. 2017. Disponível em http://hdl.handle.net/20.500.11816/2819. Acesso em: 17 de nov de 2021.

12. Mokhtar SM, Jalil LA, Noor NM. Autotransplantation of Ectopic Permanent Maxillary Incisors. Hindawi Publishing Corporation. 2017 